Research Paper

\title{
Genotype-Phenotype Analysis of CYP2CI9 in Healthy Saudi Individuals and its Potential Clinical Implication in Drug Therapy
}

\author{
Leena H Saeed ${ }^{1}$ and Ahmed Y Mayet ${ }^{2} \bowtie$ \\ 1. King Fahad Medical City, P.O. Box 59046, Riyadh 11525, Kingdom of Saudi Arabia \\ 2. King Saud University, College of Pharmacy, P.O.Box 2457, Riyadh 11451, Kingdom of Saudi Arabia
}

$\square$ Corresponding author: Ahmed Mayet, Pharm.D, BCSP, BCNSP, Associate Professor, King Saud University, College of Pharmacy, P.O. Box 2457, Riyadh 11451, Kingdom of Saudi Arabia. Tel: +966507467280; Fax +96614671985; Email: iymayet@gmail.com or iymayet@ksu.edu.sa

() Ivyspring International Publisher. This is an open-access article distributed under the terms of the Creative Commons License (http://creativecommons.org/ licenses/by-nc-nd/3.0/). Reproduction is permitted for personal, noncommercial use, provided that the article is in whole, unmodified, and properly cited.

Received: 2013.05.30; Accepted: 2013.07.29; Published: 2013.08.30

\begin{abstract}
CYP2C19 is a cytochrome P450 enzyme, which is involved in the metabolism of some clinically important medications and is encoded by a highly polymorphic gene. There is no available data on the distribution of the CYP2C19*4 and *17 mutant alleles in the Saudi Arabian population. The aim of the study was to determine different CYP2C19 mutant allele $(* 2, * 4$ and $* 17)$ frequencies in healthy Saudi subjects and to determine genotype frequencies for these mutations. The CYP2CI9 genotypes were then classified into phenotypes. Result: In $20 \mathrm{I}$ adults of Saudi ethnicity, the allele frequencies were CYP2CI $9 * 1$ (62.9\%), *17 (25.7\%), *2 (II.2\%) and *4 (0.2\%). The most prevalent genotype combinations were CYP2CI9*I/*I $(40.3 \%)$ and $* 1 / * 17(30.4 \%)$. The distribution of CYP2C19 phenotypes was divided into extensive metabolizers (EM) $77.6 \%$, intermediate metabolizers (IM) $14.9 \%$, ultra-rapid metabolizers (UM) $7 \%$ and poor metabolizers (PM) $0.4 \%$. This finding has important clinical implications for the use of CYP2CI9 metabolized medications in the Saudi population and further studies are needed.
\end{abstract}

Key words: cytochrome P450, genotype, phenotype, CYP2C19, polymorphism

\section{Introduction}

CYP2C19 is a cytochrome P450 enzyme involved in the metabolism of some clinically important medications. (1). There is an association between CYP $\mathrm{P} 450$-based genetic variation and the outcome of drug therapy, adverse drug reactions and therapeutic failures. The genes encoding for CYP2C19 are in polymorphic expression (2), with 30 variant alleles for CYP2C19 found to date (3). The CYP2C19 allele frequencies and genotype distribution were derived by gene counting. The CYP2C19 genotypes were classified into four phenotypes: (1) extensive metabolizer (EM) carrying normal function alleles (CYP2C19*1/ *1, *1/*17, *2/*17, *4/ ${ }^{*} 17$ ); (2) intermediate metabolizer (IM) carrying one loss-of-function allele $\left({ }^{*} 1 /{ }^{*} 2,{ }^{*} 1 /{ }^{*} 4\right)$;
(3) poor metabolizer (PM) carrying two loss-of-function alleles $\left({ }^{*} 2 /{ }^{*} 2,{ }^{*} 2 /{ }^{*} 4,{ }^{*} 4 /{ }^{*} 4\right)$ and $(4)$ ultra rapid metabolizer (UM) for alleles $\left({ }^{*} 17 /{ }^{*} 17\right)$.

The alleles *2, *3, and *4 are associated with decreased metabolism of the substrates (drugs), although the * 4 allele is uncommon $(4,5,6)$. The CYP2C19 mutant alleles * 4 and ${ }^{*} 17$ have not been well studied in most populations. The frequency of polymorphic alleles shows distinct inter-ethnic variation.

Some examples of commonly prescribed drugs metabolized by CYP2C19P are as follows: the antiplatelet drug (clopidogrel), proton pump inhibitors (omeprazole, lansoprazole), anticonvulsants (phenytoin, diazepam), selective serotonin reuptake inhibitor 
(citalopram), and the tricyclic antidepressants (amitriptyline, clomipramine) $(7,8,9,10,11)$. Recent studies have shown that CYP2C19 polymorphisms have caused a diverse responsiveness to clopidogrel (12, 13). The risk of cardiovascular events is increased in patients who are PM (carrying at least one CYP2C19*2 allele) despite patients receiving adequate doses of an antiplatelet agent, clopidogrel $(14,15)$. In contrast, patients carrying the CYP2C19*17 * 17 allele with UM phenotype had greater protection from clopidogrel treatment after acute myocardial infarction with extensive platelet activity $(16,17)$. A reverse occurrence was noted in the treatment of peptic ulcer disease with PPIs. A greater acid suppression was seen in patients who were PM carrying at least one CYP2C19*2 allele whereas poor acid suppression was noted in UM patients carrying CYP2C19 * 17 (*17 allele in patients treated with PPIs $(18,19)$.)

To our knowledge, only a single study has been published on the prevalence of $* 2$ and $* 3$ mutations related to the genetic polymorphism of CYP2C19 in the Saudi population in 1997 (20). No information is available on the genotyping of CYP2C19 mutants * 4 and ${ }^{*} 17$ alleles in this population.

The aim of the study was to determine different CYP2C19 mutant allele $\left({ }^{*} 2,{ }^{*} 4\right.$ and $\left.{ }^{*} 17\right)$ frequencies in healthy Saudi subjects and to determine genotype frequencies for these mutations. The CYP2C19 genotypes were then classified into phenotypes. We also compared our result with other population genetic polymorphisms of CYP2C19. The study results should allow us in future to predict adverse effects and to optimize treatment of medications metabolized through CYP2C19 in our population.

\section{Materials and Methods}

\section{Study population}

The study included 201 adults of Saudi ethnic origin (100 male and 101 female) aged 18 to 65 years between 1 August 2011 and 7 August 2011. The subjects were recruited randomly from King Fahad Medical City Blood Donation Center, Riyadh, Saudi Arabia. Subjects with any types of medical illness, organ transplant, drug or alcohol addiction, as well as pregnant females were excluded from the study. A prospective cross sectional study design was followed.

The study was approved by the Institutional Review Board of the hospital; all subjects were informed, both verbally and in writing, about the experimental procedures, confidentiality, and the purpose of the study. Written informed consents were obtained from all participants prior to entering the study.

\section{Genotyping of CYP2CI9}

A blood sample $(3 \mathrm{~mL})$ was drawn from each subject into an EDTA tube and DNA was extracted using the QIAGEN DNA Isolation Kit (Qiagen, Germany) according to the manufacturer's instructions. Validated TaqManâ Master Mix and TaqManâ genotyping assay (4324018 Applied Biosystems, USA) were used to discriminate CYP2C19 for the following single-nucleotide polymorphism (SNPs): G681A (rs4244285), A1G (rs28399504), and C-806T (rs12248560) to characterize *2, *4, and *17 alleles, respectively. Polymerase chain reaction amplification for all single nucleotide polymorphisms was performed in $25 \mu \mathrm{L}$ reactions with $20 \mathrm{ng}$ of template DNA, 1X Taqmanâ Universal Master Mix (Applied Biosystems, USA), 1X each primer and probe assay, and water qsp. Thermal cycling was initiated with a first denaturation step of $10 \mathrm{~min}$ at $95^{\circ} \mathrm{C}$, followed by 50 cycles of denaturation at $92^{\circ} \mathrm{C}$ for $15 \mathrm{~s}$ and annealing at $60^{\circ} \mathrm{C}$ for $1.30 \mathrm{~min}$. The allele detection process was performed for $1.30 \mathrm{~min}$ at $60^{\circ} \mathrm{C}$ on a Fast 7500 Real-Time PCR System (Applied Biosystems, USA) to determine the allelic discrimination.

\section{Statistical analysis}

SPSS statistical package version 19.0 was used for data analysis. Chi-square and Fisher's exact tests were used to compare the allele and genotype frequencies and descriptive analysis was used to compare allele frequencies between the Saudi population and published data of other populations. The Har$\mathrm{dy}$-Weinberg equation was used for the assessment of predicted frequencies of genotypes. A p-value of < 0.05 was deemed to represent statistical significance and confidence intervals of $95 \%$ were determined.

\section{Results}

The allele frequencies of CYP2C19*1, *2, *4, and *17 and genotype frequencies in the Saudi Arabian population are shown in Table 1 . CYP2C19*1 was the most frequently identified allele $(253 / 402,62.9 \%)$ and $81(40.3 \%)$ subjects were homozygous for the CYP2C19*1 *1 allele. CYP2C19*17 was the most common identified variant allele (103/402, 25.7\%) 14 $(7.0 \%)$ subjects were homozygous for the CYP2C19*17 ${ }^{*} 17$ and $14(7.0 \%)$ subjects were heterozygous CYP2C19*2 *17 allele. CYP2C19*2 was the second most common variant allele in our population $(45 / 402,11.2 \%) ; 29(14.5 \%)$ subjects were heterozygous for CYP2C19*1*2, $14(7 \%)$ subjects were heterozygous for CYP2C19*2*17, and only one was homozygous for CYP2C19*2*2. No subjects were homozygous for the CYP2C19*4 mutant allele and one subject was heterozygous for CYP2C19 * $1 * 4$. 
Subjects were divided into 4 phenotypes for CYP2C19 polymorphism: EM, IM, UM, and PM. The distribution of CYP2C19 phenotypes were $77.6 \%$, $14.9 \%, 7 \%$ and $0.5 \%$ for EM, IM, UM, and PM respectively. When comparing PM, IM, EM, and UM distribution of CYP2C19 phenotypes, we found a significant difference in phenotype distribution among four groups $(p<0.05)$. There were no significant associations between phenotypes and gender in our subjects (Table 2). The expected frequencies of CYP2C19 genotypes in the Saudi Arabian population were found not to deviate from the Hardy-Weinberg equilibrium. The majority of subjects included in the study were from the central region of Saudi Arabia (84\%) followed by South region (8\%), East and West regions $(3 \%)$ each and North region $(8 \%)$. The genotyping data for the Saudi Arabian sample was compared with previously studied populations to determine differences between populations (Table 3). The allele frequency of CYP2C19*2 in our study $(11.2 \%)$ was not statistically different $(p>0.05)$ from the previous study conducted by Goldstein JA et al on Saudi population (20). Also the allele frequency of CYP2C19*2 in the Saudi Arabian population (11.2\%) was not statistically different $(p>0.05)$ from that of other European ethnic groups. For example, a similar distribution was found in Romanian $(13.7 \%)$, Danish $(15.0 \%)$, German (15.2\%), Russian (11.4\%), Italian (11.9\%), and Portuguese ethnic groups $(13.0 \%)(21,22,23,24,25,26)$. In addition, we did not find any significant differences $(p>0.05)$ in the CYP2C19*2 allele frequency when comparing our population with other Middle East ethnicities such as Iranian (14\% ), Israeli (15\%), Turkish $(12 \%)$, Lebanese $(13 \%)$ and Egyptian people $(10.9 \%)(29,30,31,32,33)$. In East and South Asian groups (Chinese, Japanese, Koreans and Thai), the CYP2C19*2 allele frequencies (range: $24.9 \%-29.0 \%$ ) were significantly higher than seen in the Saudi Arabian population $(\mathrm{p}<0.05)(34,35,36,37,38)$. People of African origin (Tanzanians and African-Americans) also had a significantly higher frequency of the CYP2C19*2 allele (average of 18\%) compared to the Saudi group $(11.2 \%$; $p<0.05)(39,40,41,42)$. South American ethnic groups (Bolivians and Columbians) have a slightly lower CYP2C19*2 allele frequency (average of $8 \%$ ) than our Saudi population, although there were statistically significant differences $(p<0.05)$ $(43,44)$.

Table I. Frequencies of CYP2C19 alleles and genotypes in the Saudi population sample $(n=201)$

\begin{tabular}{|c|c|c|c|c|c|}
\hline CYP2C19 & Allele & Frequency & $\begin{array}{l}95 \% \text { Confidence inter- } \\
\text { val }\end{array}$ & Actual number & $\begin{array}{l}\text { Expected number by } \\
\text { Hardy-Weinberg law }\end{array}$ \\
\hline \multirow[t]{5}{*}{ Alleles } & *1 & 0.629 & $0.585-0.674$ & 253 & $\mathrm{~N} / \mathrm{A}$ \\
\hline & *17 & 0.257 & $0.216-0.299$ & 103 & $\mathrm{~N} / \mathrm{A}$ \\
\hline & *2 & 0.112 & $0.082-0.147$ & 45 & $\mathrm{~N} / \mathrm{A}$ \\
\hline & *4 & 0.002 & $0.000-0.007$ & 1 & $\mathrm{~N} / \mathrm{A}$ \\
\hline & Total & 1.00 & & 402 & $\mathrm{~N} / \mathrm{A}$ \\
\hline Phenotypes & Genotypes & & & & \\
\hline \multirow[t]{5}{*}{ EM } & *1*1 & 0.403 & $0.338-0.468$ & $81(\%)$ & $79.6131^{a}(\%)$ \\
\hline & $* 1 * 17$ & 0.304 & $0.239-0.363$ & $61(\%)$ & $64.8233^{a}(\%)$ \\
\hline & $* 2 * 17$ & 0.07 & $0.04-0.104$ & $14(\%)$ & $11.5298 \mathrm{a}(\%)$ \\
\hline & *4*17 & & & $0(\%)$ & $0.2562^{\mathrm{a}}(\%)$ \\
\hline & Total & 0.776 & & 156 & \\
\hline \multirow[t]{3}{*}{ IM } & $* 1 * 2$ & 0.145 & $0.100-0.194$ & $29(\%)$ & $28.3208^{a}(\%)$ \\
\hline & *1*4 & 0.004 & $0.00-0.015$ & $1(\%)$ & $0.6293^{\mathrm{a}}(\%)$ \\
\hline & Total & 0.149 & & $30(\%)$ & \\
\hline \multirow[t]{2}{*}{ UM } & *17*17 & 0.07 & $0.04-0.104$ & $14(\%)$ & $13.1952^{a}(\%)$ \\
\hline & Total & 0.07 & & 14 & \\
\hline \multirow[t]{5}{*}{ PM } & $* 2 * 2$ & 0.004 & $0.00-0.015$ & $1(\%)$ & $2.5186^{a}(\%)$ \\
\hline & $* 2 * 4$ & & & $0(\%)$ & $0.1119 \mathrm{a}(\%)$ \\
\hline & ${ }^{*} 4 * 4$ & & & $0(\%)$ & $0.0012^{\mathrm{a}}(\%)$ \\
\hline & Total & 0.004 & & 1 & \\
\hline & Overall Total & 1.00 & & 201 & 200.9994 \\
\hline
\end{tabular}

Abbreviations: PM, Poor metabolizer; IM, Intermediate metabolizer; EM, Extensive metabolizer; UM, Ultra rapid metabolizer, N/A = not applicable

a Represents no statistically significant difference between actual number and expected number by Hardy- Weinberg law in genotype distribution 
Table 2. Association between phenotypes and subject's average age and gender and phenotype distribution in the Saudi population sample $(n=201)$

\begin{tabular}{|c|c|c|c|c|c|}
\hline Phenotypes & PM & IM & EM & UM & P-value \\
\hline Phenotype distribution & 1 & 30 & 156 & 14 & $<0.05$ \\
\hline Average age (y) & 62 & $41.2 \pm 18.1$ & $38.7 \pm 14.9$ & $38.4 \pm 13.4$ & $>0.05$ \\
\hline Gender $(\mathrm{M} / \mathrm{F})$ & $1 / 0$ & $16 / 14$ & 74 / 82 & $5 / 9$ & $\geq 0.55$ \\
\hline
\end{tabular}

Abbreviations: PM, Poor metabolizer; IM, Intermediate metabolizer; EM, Extensive metabolizer; UM, Ultra rapid metabolizer

Table 3. Comparison of allele frequencies between Saudi Arabian and other populations

\begin{tabular}{|c|c|c|c|c|c|}
\hline \multirow[t]{2}{*}{ Population } & \multirow[t]{2}{*}{ Sample size } & \multicolumn{3}{|c|}{ CYP2C19 allele frequency, $\%$} & \multirow[t]{2}{*}{ Reference } \\
\hline & & $* 2$ & $* 4$ & ${ }^{*} 17$ & \\
\hline Saudi Arabian & 201 & 11.2 & 0.2 & 25.7 & Our study \\
\hline Saudi Arabian & 97 & 15 & - & - & 20 \\
\hline Romanian & 200 & 13.7 & 0.25 & - & 21 \\
\hline Danish & 276 & 15.0 & - & 20.1 & 22 \\
\hline German & 237 & 15.2 & - & 25.5 & 23 \\
\hline Russian & 290 & 11.4 & - & - & 24 \\
\hline Italian & 360 & 11.9 & - & - & 25 \\
\hline Portuguese & 153 & 13.0 & - & - & 26 \\
\hline Greece & 283 & - & - & 19.6 & 27 \\
\hline Polish & 125 & 11.6 & - & 27.2 & 28 \\
\hline Israeli & 140 & 15.0 & - & - & 29 \\
\hline Iranian & 200 & 14.0 & - & - & 30 \\
\hline Turkish & 404 & 12.0 & - & - & 31 \\
\hline Lebanese & 161 & 13.0 & - & - & 32 \\
\hline Egyptian & 247 & 10.9 & - & - & 33 \\
\hline Chinese & 384 & $24.9^{++}$ & - & $1.2^{++}$ & 34 \\
\hline Thai & 774 & $29.0^{++}$ & - & - & 35 \\
\hline North Indian & 300 & $26.2^{++}$ & - & - & 36 \\
\hline Japanese & 265 & $27.9^{++}$ & - & $1.3^{++}$ & 37 \\
\hline Korean & 271 & $28.4^{++}$ & - & $1.5^{++}$ & 38 \\
\hline Ethiopian & 114 & 14.0 & - & - & 39 \\
\hline Tanzanian & 251 & 18.0 & - & - & 40 \\
\hline African-American & 236 & 18.2 & - & - & 41 \\
\hline African-American & 114 & - & - & 21.0 & 42 \\
\hline Columbian & 198 & 8.7 & - & - & 43 \\
\hline Bolivian & 778 & 7.8 & - & - & 44 \\
\hline
\end{tabular}

Represents either not tested or published data not available

${ }^{++}$Represents statistically significant difference in comparison with current data $(\mathrm{p}<0.05)$

There is very limited published data available from other populations on mutant alleles * 4 and * 17 making it difficult to compare our data with other ethnicities. We have no data from most of the other populations for the frequency of the CYP2C19*4 allele to compare except for the Romanians $(0.25 \%)$, and they were comparable to our Saudi population $(0.2 \%)$ (21).

The allele frequency of CYP2C19*17 in the Saudi Arabian population (25.7\%) was not statistically different ( $p>0.05)$ from than that seen in European ethnic groups; a similar distribution was found in Danish
(20.1\%), German (25.5\%), Greek (19.6\%), and Polish $(27.2 \%)$ populations $(22,23,27,28)$. In East and South Asian groups (Chinese, Japanese, and Koreans), the CYP2C19*2 allele frequencies (range: $1.2 \%-1.5 \%$ ) were significantly lower than seen in the Saudi Arabian population $(\mathrm{p}<0.05)(34,37,38)$.

\section{Discussion}

The CYP2C19 mutant alleles * 4 and * 17 have not been studied well in the worldwide population. This study was a first attempt to determine the distribution of CYP2C19 mutant alleles *4 and *17 in Saudi Arabia, 
as there were no such data available on our population.

Our study result indicates that approximately $85 \%$ of the Saudi population (16.5 million), by extrapolation, would be considered as extensive metabolizers $(\mathrm{EM}+\mathrm{UM})$ for CYP2C19 drug substrates. Studies have shown that CYP2C19 genetic variation represents a key factor influencing the pharmacokinetics of the drugs that are substrates to CYP2C19. A profound acid suppression and high peptic ulcer healing rate was noted in Japanese and some Caucasians patients with CYP2C19 *2 *2 and ${ }^{*} * 4$ mutations (PM phenotype) with PPI treatments $(18,45)$. Other studies have shown that EMs metabolize PPIs at a rate that requires much higher doses than PMs (up to four times) to reach similar serum concentrations and effects $(8$, 9 ). Based on current predictive model, one would extrapolate that treatment of peptic ulcer disease with conventional doses of PPIs in the Saudi population who are predominantly $(77.6 \%) \mathrm{EM}\left({ }^{*} 1 /{ }^{*} 1\right.$ genotype or subjects with*17 mutations) would produce a reduced acid-inhibitory effect. This may lead to therapeutic failure in our population however; further studies are needed to explore such effects.

We have described in the introduction some clinically important antiepileptic drugs, tricyclic antidepressants, selective serotonin reuptake inhibitors and benzodiazepines that are all substrates to CYP2C19 (11,12,13,14,15). Our Saudi population with EM (77.6\%) and UM (14\%) theoretically will have significantly decreased drug exposure as the concentrations of these drugs may decrease by rapidly converting into inactive metabolites with a possible reduction of their therapeutic effects. Prior to initiating treatment with such drugs, CYP2C19 genotyping could be a reasonable approach, with respect to optimizing dosage adjustments, improving treatment efficacy, and optimizing treatment cost effectiveness. Also during the treatment with such drugs, therapeutic drug monitoring can improve treatment efficacy.

Clopidogrel is an inactive prodrug that requires hepatic bioactivation via CYP2C19 to exert its effect. This process is hindered in PM and decreases the production of the active metabolite $(14,15)$. The risk of cardiovascular events is increased in patients who are PM (carrying at least one CYP2C19*2 allele) despite patients receiving adequate doses of an antiplatelet agent, clopidogrel $(12,13,14,15)$. Since our population comprise of only $0.5 \% \mathrm{PM}$, they will be least affected by clopidogrel responsiveness, however additional studies are needed to recognize such effects in our population.

In conclusion, CYP2C19*1 was the most frequently identified allele $(62.9 \%)$ and CYP2C19*17 was the most commonly identified variant allele (25.7\%) in a sample of 201 ethnic Saudi Arabians. The predicted distributions of CYP2C19 phenotypes were $77.6 \%$ for EMs and only $0.5 \%$ for PMs. This finding has important clinical implications for the use of CYP2C19 metabolized medications in the Saudi population. Further studies are needed to explore the clinical effect of different drugs in relation to CYP2C19 polymorphic genotype distribution in the Saudi population. Our study result can also be used as a benchmark for future comparisons with other populations for the prevalence of CYP2C19 variant alleles.

\section{Acknowledgements}

This project is supported by the "King Saud University (KSU) - Liver Disease Research Center". We would like to acknowledge Rosemary Collier who provided editing support. In addition we also like to thanks Dr. Mahasen A. Radwan, Ph.D., Dr. Geyhad El Ghazali MD, Ph.D., and Dr. Rajaa A. Mirghani for providing technical support.

\section{Competing Interests}

The authors have declared that no competing interest exists.

\section{References}

1. Daly AK. Pharmacogenetics of the major polymorphic metabolizing enzymes. Fundam Clin Pharmacol. 2003; 17: 27-41.

2. Goldstein JA. Clinical relevance of genetic polymorphisms in the human CYP2C subfamily. Br J Clin Pharmacol. 2001; 52: 349-55.

3. [Internet] Homepage of the Human Cytochrome P450 (CYP) Allele Nomenclature Committee (CYP2C19) 2006 [cited 2006]. http://www.imm.ki.se/cypalleles/cyp2c19.htm

4. Aynacioglu AS, Brockmöller J, Bauer S, Sachse C, Güzelbey P, Ongen Z et al. Frequency of cytochrome P450 CYP2C9 variants in a Turkish population and functional relevance for phenytoin. Br J Clin Pharmacol. 1999; 48: 409-15.

5. Tanigawara Y, Aoyama N, Kita T, Shirakawa K, Komada F, Kasuga M et al. CYP2C19 genotype-related efficacy of omeprazole for the treatment of infection caused by Helicobacter pylori. Clin Pharmacol Ther. 1999; 66: 528-34

6. Xie HG, Stein CM, Kim RB, Wilkinson GR, Flockhart DA, Wood AJ. Allelic, genotypic and phenotypic distributions of S-mephenytoin 4'-hydroxylase (CYP2C19) in healthy Caucasian populations of European descent throughout the world. Pharmacogenetics. 1999; 9: 539-49.

7. Andersson T, Holmberg J, Rohss K, Walan A. Pharmacokinetics and effect on caffeine metabolism of the proton pump inhibitors, omeprazole, lansoprazole, and pantoprazole. Br J Clin Pharmacol. 1998; 45: 369-75.

8. Gardiner SJ, Begg EJ. Pharmacogenetics, drug-metabolizing enzymes, and clinical practice. Pharmacol Rev. 2006; 58: 521-90.

9. Ono S, Hatanaka T, Miyazawa S, Tsutsui M, Aoyama T, Gonzalez FJ et al. Human liver microsomal diazepam metabolism using cDNA-expressed cytochrome P450s: role of CYP2B6, 2C19 and the 3A subfamily. Xenobiotica. 1996; 26: 1155-66.

10. Marian SP, Simona B, Fraga SP. Individualized drug response related to genetic variations of cytochrome P450 isoforms and other enzymes. Farmacia. 2010; 58: 245-254.

11. Andries A, Cioaca D, Guțiu IA, Oprea I, Radulescu F, Georgescu A. Detection of cyp $2 \mathrm{~d} 6^{*} 6$ allele by real time polymerase chain reaction in Romanian population. Farmacia. 2010; 58: 353-361.

12. Mega JL, Close SL, Wiviott SD, Shen L, Hockett RD, Brandt JT et al. Cytochrome p450 polymorphisms and response to clopidogrel. N Engl J Med. 2009; 360: 354-62

13. Simon T, Verstuyft C, Mary-Krause M, Quteineh L, Drouet E, Meneveau $\mathrm{N}$ et al. Genetic determinants of response to clopidogrel and cardio-vascular events. N Engl J Med. 2009; 360: 363-75. 
14. Collet JP, Hulot JS, Pena A, Villard E, Esteve JB, Silvain J et al. Cytochrome P4502C19 polymorphism in young patients treated with clopidogrel after myocardial infarction: a cohort study. Lancet. 2009; 373: 309-17.

15. Trenk D, Hochholzer W, Fromm MF, Chialda LE, Pahl A, Valina CM et al. Cytochrome P4502C19 681G $>$ A polymorphism and high on-clopidogrel platelet reactivity associated with adverse 1-year clinical outcome of elective percutaneous coronary intervention with drug-eluting or bare-metal stents. J Am Coll Cardiol. 2008; 51:1925-34.

16. Sibbing D, Koch W, Gebhard D, Schuster T, Braun S, Stegherr J et al. Cytochrome $2 \mathrm{C} 19^{*} 17$ allelic variant, platelet aggregation, bleeding events, and stent thrombosis in clopidogrel-treated patients with coronary stent placement. Circulation. 2010; 121: 512-518.

17. Sim SC, Risinger C, Dahl ML, Aklillu E, Christensen M, Bertilsson L et al. A common novel CYP2C19 gene variant causes ultra rapid drug metabolism relevant for the drug response to proton pump inhibitors and antidepressants. Clin Pharmacol Ther. 2006; 79: 103-113.

18. Kawabata H, Habu Y, Tomioka H, Kutsumi H, Kobayashi M, Oyasu K et al. Effect of different proton pump inhibitors, differences in CYP2C19 genotype and antibiotic resistance on the eradication rate of Helicobacter pylori infection by a 1-week regimen of proton pump inhibitor, amoxicillin and clarithromycin. Aliment Pharmacol Ther. 2003, 17: 259-264.

19. Furuta $T$, Shirai $N$, Sugimoto $M$, Ohashi $K$, Ishizaki T. Pharmacogenomics of proton pump inhibitors. Pharmacogenomics. 2004; 5: 181-202.

20. Goldstein JA, Ishizaki T, Chiba K, de Morais SM, Bell D, Krahn PM, et al. Frequencies of the defective CYP2C19 alleles responsible for the mephenytoin poor metabolizer phenotype in various Oriental, Caucasian, Saudi Arabian and American black populations. Pharmacogenetics. 1997; 7: 59-64.

21. Anca DB, Adrian PT, Radu AP, Mariela SM, Claudia FM, Corina IB et al. Screening for CYP2C19*2, *3 and *4 Gene variants in Romanian population study group. Farmacia. 2010; 58: 806-17.

22. Pedersen RS, Brasch-Andersen C, Sim SC, Bergmann TK, Hailing J, Petersen MS et al. Linkage disequilibrium between the CYP2C19*17 allele and wildtype CYP2C8 and CYP2C9 alleles: identification of CYP2C haplotypes in healthy Nordic populations. Eur J Clin Pharmacol. 2010; 66: 1199-1205.

23. Geisler T, Schaeffeler E, Dippon J, Winter S, Buse V, Bischofs C et al. CYP2C19 and nongenetic factors predict poor responsiveness to clopidogrel loading dose after coronary stent implantation. Pharmacogenomics. 2008; 9: 1251-1259.

24. Gaikovitch EA, Cascorbi I, Mrozikiewicz PM, Brockmoller J, Frotschl R, Kopke $\mathrm{K}$ et al. Polymorphisms of drug-metabolizing enzymes CYP2C9, CYP2C19, CYP2D6, CYP1A1, NAT2 and of P-glycoprotein in a Russian population. Eur J Clin Pharmacol. 2003; 59: 303-312.

25. Scordo MG, Caputi AP, D'Arrigo C, Fava G, Spina E. Allele and genotype frequencies of CYP2C9, CYP2C19 and CYP2D6 in an Italian population. Pharmacol Res. 2004; 50: 195-200.

26. Oliveira E, Marsh S, van Booven DJ, Amorim A, Prata MJ, McLeod HL. Pharmacogenetically relevant polymorphisms in Portugal. Pharmacogenomics. 2007; 8: 703-12.

27. Ragia G, Arvanitidis KI, Tavridou A, Manolopoulos VG. Need for reassessment of reported CYP2C19 allele frequencies in various populations in view of CYP2C19*17 discovery: the case of Greece. Pharmacogenomics. 2009; 10: 43-49.

28. Kurzawski M, Gawronska-Szldarz B, Wrzesniewska J, Siuda A, Starzynska T, Drozdzik M. Effect of CYP2C19*17 gene variant on Helicobacter pylori eradication in peptic ulcer patients. Eur J Clin Pharmacol. 2006; 62: 877-880

29. Sviri S, Shpizen S, Leitersdorf E, Levy M, Caraco Y. Phenotypic-genotypic analysis of CYP2C19 in the Jewish Israeli population. Clin Pharmacol Ther. 1999; 65: 275-82.

30. Zand N, Tajik N, Moghaddam AS, Milanian I. Genetic polymorphisms of cytochrome P450 enzymes 2C9 and 2C19 in a healthy Iranian population. Clin Exp Pharmacol Physiol. 2007; 34: 102-105.

31. Aynacioglu A S, Sachse C, Bozlcurt A, Kortunay S, Nacak M, Schroder T, et al. Low frequency of defective alleles of cytochrome P450 enzymes 2C19 and 2D6 in the Turkish population. Clin Pharmacol Ther. 1999; 66: 185-192.

32. Djaffar Jureidini I, Chamseddine N, Keleshian S, Naoufal R, Zahed L, Hakime N. Prevalence of CYP2C19 polymorphisms in the Lebanese population. Mol Biol Rep. 2011; 38: 5449-5452.

33. Hamdy SI, Hiratsuka M, Narahara K, El-Enany M, Moursi N, Ahmed MS et al. Allele and genotype frequencies of polymorphic cytochromes P450 (CYP2C9, CYP2C19, CYP2E1) and dihydropyrimidine dehydrogenase (DPYD) in the Egyptian population. Br J Clin Pharmacol. 2002; 53 : 596-603.
34. Chen L, Qin S, Xie J, Tang J, Yang L, Shen W, et al. Genetic polymorphism analysis of CYP2C19 in Chinese Han populations from different geographic areas of mainland China. Pharmacogenomics. 2008; 9: 691-702.

35. Tassaneeyakul W, Mahatthanatrakul W, Niwatananun K, Na-Bangchang $\mathrm{K}$, Tawalee A, Krikreangsak N et al. CYP2C19 genetic polymorphism in Thai, Burmese and Karen populations. Drug Metab Pharmacokinet. 2006; 21: 286-290

36. Yadav SS, Ruwali M, Shah PP, Mathur N, Singh RL, Pant MC et al. Association of poor metabolizers of cytochrome P450 2C19 with head and neck cancer and poor treatment response. Mutat Res. 2008; 644: 31-37.

37. Sugimoto $\mathrm{K}$, Lino $\mathrm{T}$, Yamazalci $\mathrm{H}$, Tateishi $\mathrm{T}$. Limited frequency of the CYP2C19*17 allele and its minor role in a Japanese population. Br J Clin Pharmacol. 2008; 65: 437-439.

38. Kim KA, Song WK, Kim KR, Park JY. Assessment of CYP2C19 genetic polymorphisms in a Korean population using a simultaneous multiplex pyrosequencing method to simultaneously detect the CYP2C19*2, CYP2C19*3, and CYP2C19*17 alleles. J Clin Pharm Ther. 2010; 35: 697-703.

39. Persson I, Aklillu E, Rodrigues F, Bertilsson L, Ingelman-Sundberg M. S-mephenytoin hydroxylation phenotype and CYP2C19 genotype among Ethiopians. Pharmacogenetics. 1996; 6: 521-6.

40. Herrlin K, Massele AY, Jande M, Alm C, Tybring G, Abdi YA, et al. Bantu Tanzanians have a decreased capacity to metabolize omeprazole and mephenytoin in relation to their CYP2C19 genotype. Clin Pharmacol Ther. 1998; 64: 391-401.

41. Luo HR, Poland RE, Lin KM, Wan YJ. Genetic polymorphism of cytochrome P450 2C19 in Mexican Americans: a cross-ethnic comparative study. Clin Pharmacol Ther. 2006; 80: 33-40.

42. Kearns GL, Leeder JS, Gaedigk A. Impact of the CYP2C19*17 allele on the pharmacokinetics of omeprazole and pantoprazole in children: evidence for a differential effect. Drug Metab Dispos. 2010; 38: 894-897.

43. Isaza C, Henao J, Martinez JH, Sepúlveda Arias JC, Beltrán L. Phenotype-genotype analysis of CYP2C19 in Colombian mestizo individuals. BMC Clin Pharmacol. 2007; 7: 6.

44. Bravo-Villalta HV, Yamamoto K, Nakamura K, Baya A, Okada Y, Horiuchi R. Genetic polymorphism of CYP2C9 and CYP2C19 in a Bolivian population: an investigative and comparative study. Eur J Clin Pharmacol. 2005; 61: 179-84.

45. Kawamura M, Ohara S, Koike T, Iijima K, Suzuki J, Kayaba S, et al. The effects of lansoprazole on erosive reflux oesophagitis are influenced byCYP2C19 polymorphism. Aliment Pharmacol Ther. 2003; 17: 965-973.

46. Furuta T, Shirai N, Xiao F, Ohashi K, Ishizaki T. Effect of high-dose lansoprazole on intragastic $\mathrm{pH}$ in subjects who are homozygous extensive metabolizers of cytochrome P4502C19. Clin Pharmacol Ther. 2001; 70: 484-492.

47. Kita T, Sakaeda T, Aoyama N, Sakai T, Kawahara Y, Kasuga M, et al. Optimal dose of omeprazole for CYP2C19 extensive metabolizers in anti-Helicobacter pylori therapy: pharmacokinetic considerations. Biol Pharm Bull. 2002; 25: 923-927.

48. Yamamoto K, Hokimoto S, Chitose T, Morita K, Ono T, Kaikita K et al. Impact of CYP2C19 polymorphism on residual platelet reactivity in patients with coronary heart disease during antiplatelet therapy. J Cardiol. 2011; 57: 194-201

49. Frére $\mathrm{C}$, Cuisset $\mathrm{T}$, Gaborit B, Alessi MC, Hulot JS. The CYP2C19*17 allele is associated with better platelet response to clopidogrel in patients admitted for non-ST acute coronary syndrome. J Thromb Haemost. 2009; 7(8): 1409-11. 